\title{
Metodologias
}

\section{Questões metodológicas para o estudo das vidas narrativizadas: aplicação às narrativas de empreendedores sociais ${ }^{1}$}

\section{Methodological issues for the study of narrativized lives: application to narratives of social entrepreneurs}

VANDER CASAQUI

Professor do Programa de Pós-Graduação em Comunicação e Práticas de Consumo - Escola Superior de Propaganda e Marketing (ESPM) São Paulo, SP, Brasil.

<vcasaqui@yahoo.com.br>

\section{RESUMO}

Este artigo trata das questões contextuais, conceituais e metodológicas para o estudo das narrativas de empreendedores sociais. Trata-se de parte de um estudo mais amplo de pós-doutoramento, que aborda o empreendedorismo social na comparação entre os cenários brasileiro e português. O quadro teórico desta pesquisa se baseia nas discussões acerca do novo espírito do capitalismo (Boltanski; Chiapello, 2009) e do papel do empreendedor social como forma de engajamento no sistema. Este papel é semantizado de acordo com o ambiente social que o abriga. A proposta metodológica é desenvolvida a partir da análise do percurso de vida, segundo Giele e Elder Jr. (1998).

Palavras-chave: Comunicação e Consumo; Empreendedorismo Social; Narrativas.

\begin{abstract}
This article treats of the contextual, conceptual and methodological issues for the study of the narratives of social entrepreneurs. It is part of broader post-doctoral research, that addresses the social entrepreneurship in comparison between Brazilian and Portuguese scenarios. The theoretical frame of this research is based on the discussion about the new spirit of capitalism (Boltanski; Chiapello, 2009) and the role of social entrepreneur as form of engagement in the system. This role is semanticized according with the social environment that shelters him. The methodological proposal is developed from the life course analysis, according Giele and Elder Jr. (1998).

Keywords: Communication and Consumption; Social Entrepreneurship; Narratives.
\end{abstract}


reflexão ora apresentada é parte de pesquisa mais ampla de pós-doutoramento, Acujo objetivo é compreender os significados do empreendedorismo social em dois contextos distintos: no Brasil e em Portugal, com predominância de agentes das cidades de São Paulo, Lisboa e Porto.

No contexto brasileiro, a imagem celebrada e celebrizada do empreendedor social (evidenciada por premiações como o Prêmio Empreendedor Social do jornal Folha de São Paulo) se estabelece no entrecruzamento com o imaginário do batalhador brasileiro (Souza, 2010), em uma zona de interinfluência: ou seja, tanto o empreendedor social ganha sentido a partir da visibilidade das trajetórias, das vidas narrativizadas dos próprios agentes, quanto o batalhador brasileiro é atualizado pela ideia do empreendedor, da alta performance (Ehrenberg, 2010) aplicada a uma causa social. No contexto português, o cenário de crise econômica vai atribuir outros matizes a esse personagem, que surge como alternativa à falência do Estado do Bem-Estar Social, em iniciativas que visam suprir carências cotidianas no ambiente em que não há espaço para a visão eufórica dessa atuação.

Em linhas gerais, o empreendedor social alia a performance e a eficácia exigidas pelo mercado ao trabalho em prol do bem comum, que, em tese, não visa o lucro, mas o bem-estar da comunidade, a inclusão e a amenização das disparidades sociais.

Neste trabalho, desenvolvemos a reflexão epistemológica e metodológica acerca das narrativas, compreendidas na perspectiva proposta por Arfuch (2010), ou seja: a vida como narração, como trajetória que dá sentido aos fragmentos da experiência, à mobilização da memória e à projeção e ancoragem subjetiva em torno do consumo cultural (Amaya, 2004). O conceito de espaço biográfico de Arfuch, que engloba tanto as biografias quanto as autobiografias, manifestações comunicacionais ajustadas ao espírito do tempo de exposição da intimidade (ou extimidade, conforme Sibilia, 2008), é organizador da investigação em torno das trajetórias de vida de empreendedores sociais. 


\section{Apontamentos sobre o empreendedorismo social}

O empreendedor social é um ator relativamente recente, que representa a lógica cultural do capitalismo contemporâneo. Eis um conceito polissêmico, que, por vezes, escapa à compreensão, quando procuramos delimitar seus traços identitários, demarcadores da diferença em relação àquilo que não é. Ao abordá-lo, emergem conceitos que ora são sobrepostos ao empreendedorismo social, ora o substituem, ora são diferenciados dele: economia social, inovação social, empresa social, negócio social. Em comum, o termo social como signo que, em tese, estabeleceria uma lógica outra para o primeiro termo ao qual se refere. Empreendedorismo, economia, inovação, empresa, negócios: estamos, obviamente, no campo semântico do sistema capitalista, das operações empresariais e nos processos baseados numa lógica de mercado e competitividade. A emergência do social no discurso capitalista, que tem raízes históricas, parece ganhar força na contemporaneidade, ao corresponder a um novo espírito do capitalismo (Boltanski; Chiapello, 2009), em que a sustentabilidade, a responsabilidade social, o ambientalismo e a cidadania parecem revestir as operações corporativas e suas mercado-lógicas. O mundo empresarial, afetado que é pela midiatização generalizada da sociedade, planeja suas entradas em cena a partir de articulações entre a estética publicitária e uma pseudoideologia revolucionária, calcada em utopias planetárias (Mattelart, 2002) e forte apelo à convocação, seja dos próprios trabalhadores a ele vinculados, seja dos consumidores de suas mercadorias.

No entanto, a retórica capitalista ganha algumas nuances quando vista a partir da lógica do empreendedorismo social. Vejamos uma definição dessa prática, a partir de uma instituição de referência no cenário português - o Instituto do Empreendedorismo Social (IES): "O IES adota como unidade de análise primordial o empreendedor social e a(s) sua(s) iniciativa(s), definindo o empreendedor social como um catalisador de 
mudança que resolve eficazmente problemas sociais"2. Ainda de acordo com o IES, são quatro os critérios-base para reconhecer um empreendimento social:

1. Resolve Problemas Sociais/Ambientais negligenciados (Missão Social/Ambiental); 2. Tem um potencial de Transformação Positiva na Sociedade a nível Social/Ambiental (Impacto Social/Ambiental); 3. Desafia a visão tradicional e utilizando modelos de negócio inovadores (Inovação); 4. Tem um potencial de crescimento elou se replicação noutro local geográfico (Escalabilidade/Replicabilidade)."

Complementa esses fatores a condição da sustentabilidade financeira da iniciativa - baseada no desenvolvimento de um modelo de negócios eficaz. As fronteiras são flutuantes quando se procura delimitar o que é empreendedorismo e o que é empreendedorismo social. Vejamos a forma como essa diferença é defendida pelo IES:

Enquanto um empreendedor comercial procura oportunidades de criar e capturar valor económico, para um empreendedor social, o foco da atenção é o problema da sociedade a resolver, mesmo que a resolução desse problema não pareça permitir fazer lucros. O empreendedor social procura maximizar a criação de valor social para a sociedade, satisfazendo a captura de valor (para si e para a sua organização) a um nível que assegure a sustentabilidade da solução a longo prazo." 
A partir da posição do IES, percebemos que o empreendedor social tem o mesmo modus operandi de um empreendedor qualquer. O que muda é, em tese, a aplicação da lógica empreendedora para resolução de problemas que, em tempos de falência do Estado Social, são, de certa forma, privatizados, deixados à responsabilidade da sociedade civil e de suas iniciativas; muda também o valor resultante de seus processos, que, se geram algum lucro, têm a função de alimentar um ciclo virtuoso de atendimento a carências sociais.

No contexto da crise que atinge Portugal, atualmente, o empreendedorismo é um tema recorrente, tanto na fala de governantes quanto na realização de eventos, concursos, premiações que fomentam a sua expansão. Diante da alternativa vaga e cada vez mais distante de um emprego formal, com boas condições salariais e estabilidade, os jovens estudantes do ensino superior, ou recentemente licenciados, recebem a convocação para criar seu próprio emprego, ou o autoemprego. No processo de inserção do pesquisador no ambiente a ser estudado, participamos de uma série de eventos itinerantes, chamada Job Party, que tem sido organizada nas principais universidades portuguesas. Nesse espaço voltado à "festa do emprego", a maioria do tempo é destinada a apresentações a respeito do empreendedorismo e do empreendedorismo social - este último, visto como opção ao primeiro emprego, expõe um contexto em que o propósito da iniciativa adquire simultaneamente o caráter de solução do problema do próprio agente. $\mathrm{O}$ empreendedor social, além de agir para resolver uma questão social específica, torna-se empreendedor de si mesmo, num cenário em que todos são instados a serem autossustentáveis, a não esperarem pelas oportunidades ou pelo apoio do Estado Social. Surgem, assim, entidades e organizações que se instauram entre o Estado e a iniciativa privada, e que gerem apoios às iniciativas empreendedoras, como é o caso do Banco de Inovação Social (BIS). Extraímos uma publicação, em sua página no Facebook, elucidativa da forma como o empreendedorismo social tem catalisado 
as projeções de futuro, que envolvem a naturalização do desmonte do Estado Social Europeu:

O Fundo de Investimento Social - Fundo BIS - vai estar aberto ao financiamento do público. Para investir em projetos que tragam respostas concretas a problemas na sociedade. Captamos, direcionamos e investimos recursos: onde vale a pena, onde haja soluções, onde a mudança acontece. Pelas melhores causas. Para que sejam sustentáveis! "5

O termo mudança é recorrente nos discursos que envolvem o empreendedorismo social, investido de uma dimensão utópica, em tom messiânico. Utopias pragmáticas, que devem apresentar resultados, demonstrar impactos quantificáveis, tornarem-se sustentáveis e replicáveis: esse é o caráter dos discursos de transformação que atravessam as práticas do empreendedorismo social, não somente em Portugal.

Lopes (2012, p. 87) sintetiza a rede de significados que compõe o espectro do termo no âmbito da situação atual da economia e da sociedade portuguesa, de maneira geral:

O empreendedorismo tem vindo, assim, a ser transformado na panaceia que solucionará os graves problemas do desemprego desencadeados pela crise, através das políticas de apoio ao empreendedorismo de base tecnológica e de inovação, e que atenuará os impactos da crise através das iniciativas solidárias do microempreendedorismo, do empreendedorismo social e do empreendedorismo económico solidário. [...] Tudo pesado, tudo leva a crer que a retórica do empreendedorismo e a tónica nas oportunidades de negócio produzidas pelas crises reforcem de forma clara o mito da autorrealização e do individualismo." 
Por meio do espectro do empreendedorismo, há um processo de responsabilização dos indivíduos, ao passo que se percebem a fragmentação social, a quebra do Estado, o abandono de um projeto de sociedade e sua atomização para dezenas, centenas, milhares de projetos concebidos, realizados e mantidos pelos esforços, ideias dos atores sociais identificados com o empreendedorismo social. A retórica que promove o engajamento dos novos quadros alimenta o sonho de tornar-se o próprio chefe, de conceber uma forma de trabalhar que traz realização plena, algo que seria o contraponto ao trabalho estranhado discutido por Marx (2004).

No entanto, não são necessários grandes investimentos reflexivos para perceber que, diante dessa convocação, grande parte dos jovens que não conseguiram o primeiro emprego e também os demais cidadãos que ficaram à margem do mercado formal de trabalho, não possuem aptidões para empreender, para conceber e gerir um negócio, que tem, na dinâmica capitalista, a questão de fundo da competição. Isso implica a superação de uns pelos outros, pois não há espaço para que todas as iniciativas se concretizem e sejam sustentáveis, ou seja, para que consigam gerir verbas por meio de suas operações, para manterem-se vivas sem o apoio de medidas e investimentos do Estado. O discurso da capacitação surge como uma forma de regulação e controle, pois visa à adequação dos sujeitos a práticas e modos de ver o mundo que se ajustam ao habitus (Bourdieu, 2003) do empreendedor.

O empreendedor social, além de ter capacitação técnica, habilidade gerencial e tino para promover a sustentabilidade econômica de suas iniciativas, deve estar aberto ao outro, ser alguém que se importa, que abre mão do lucro puro e simples para promover o bem comum. Esse espectro do espírito empreendedor generalizado para a sociedade como um todo é concretizado pela fragmentação e descontinuidade, por uma gama de ações que competem entre si e fazem da esfera pública um emaranhado de territorializações estabelecidas pelos empreendimentos e seus líderes. Ou seja, cada 
iniciativa promove uma edição do mundo, constitui um território a partir do qual são projetados a sociedade e os sujeitos em interação, em ação com vistas à solução dos problemas sociais.

Lopes (2012, p. 87) pondera a respeito do relevante papel que essas iniciativas desempenham, "quer na adaptação às crises, quer na sustentação da coesão social". Podemos estender essa lógica para o contexto brasileiro, que, se não vive o espectro da crise que paira sobre a Comunidade Europeia - e que atinge fortemente alguns países, como é o caso de Portugal, um dos cenários da realização desta pesquisa - , está ainda distante de resolver suas desigualdades sociais. Nesse sentido, a sustentação da coesão social, tanto em Portugal como no Brasil, acaba por ser auxiliada por iniciativas de sujeitos que têm motivações, têm trajetórias de vida que se conectam as causas defendidas, e, principalmente, têm formas de narrar a própria experiência que interessam a esta pesquisa. Tratamos, a seguir, das questões epistemológicas e metodológicas que envolvem o trabalho de campo desta investigação a respeito dos empreendedores sociais, em perspectiva comparativa.

\section{Narrativas de vida de empreendedores sociais: acerca do método}

Inserido no campo da comunicação, o estudo a ser realizado é delimitado a partir das narrativas dos empreendedores sociais, na forma como concebem a própria trajetória de vida, as atividades que realizam atualmente, como compreendem o contexto em que se inserem e como projetam o país em que vivem e empreendem, pela ótica de sua forma de ação social. Dessa forma, investigar o empreendedorismo social passa por uma contextualização macrológica, um mapeamento dos percursos históricos que desembocam na configuração desse ator e na reflexão sobre o espírito do tempo que faz com que esse sujeito fale e também ecoe as vozes do lugar de fala, a partir do qual se posiciona na interação com o pesquisador. 
O enquadramento qualitativo da pesquisa está baseado na perspectiva da vida como narração, conforme a teoria de Arfuch (2010, p. 112):

O tempo mesmo se torna humano na medida em que é articulado sobre um modo narrativo. Falar do relato, então, dessa perspectiva, não remete apenas a uma disposição de acontecimentos - históricos ou ficcionais - [...], mas à forma por excelência de estruturação da vida e, consequentemente, da identidade, à hipótese de que existe, entre a atividade de contar uma história e o caráter temporal da experiência humana, uma correlação que não é puramente acidental, mas que apresenta uma forma de necessidade 'transcultural'."

Em sintonia com essa perspectiva, buscamos analisar como o empreendedor social reconstitui e articula fragmentos da existência em vida narrada, em ordenação e atribuição de sentido, na edição de um mundo próprio que vai constituí-lo a partir de um papel, de uma atividade social. Não é o foco da pesquisa a análise dos empreendimentos sociais em relação a seu impacto, à sua contribuição para a comunidade ou qualquer outro atributo que exigiria outro tipo de estudo, o que escaparia à dimensão comunicacional como a tratamos aqui. Interessa-nos analisar os discursos que envolvem essas práticas, como elas promovem uma edição do mundo, como elas correspondem ou não a certo espírito do tempo e como elas produzem significados a respeito do mundo do trabalho, das práticas de consumo, da ação humana e sua responsabilização, paixão, missão. Dois eixos de pesquisa foram eleitos: 
a) Para a análise contextual, buscamos apreender os significados culturais em jogo na atuação do empreendedor social, por meio dos discursos e manifestos que envolvem a sua prática, seja pelas instituições que incentivam e dão visibilidade às iniciativas, seja por meio dos discursos em fóruns privilegiados sobre o tema, ou nos modos de presença midiática dos empreendimentos sociais, especialmente através de seus sites de apresentação.

b) O trabalho de campo envolve a realização de entrevistas em profundidade com sujeitos identificados como empreendedores sociais, localizados por meio desses lugares de visibilidade e atribuição de valor às iniciativas e a seus realizadores. O evento Job Party foi a principal referência em Lisboa para identificação dos agentes dessa atividade, pois são tornados visíveis para a comunidade estudantil como modelos, como exemplos a serem seguidos. Por meio desses empreendedores, chegamos à indicação de outros que poderiam compor a pesquisa. Outro lugar de referência foi o site do IES, entidade que atribui um selo de qualidade a iniciativas acompanhadas por seu mapeamento das atividades de empreendedorismo social pelo território português. Por meio dessa plataforma localizamos projetos sociais na cidade do Porto, a segunda principal cidade do país. A pesquisa realizada em São Paulo, o lugar eleito no Brasil para compor esse projeto, tem como ponto de partida a referência do Mapa da Participação Cidadã 6 , que se propõe a dar visibilidade às iniciativas associadas ao empreendedorismo social.

Giele e Elder Jr. (1998) propõem o estudo do percurso, ou da trajetória de vida, a partir de quatro elementos, que são filtrados pelos sujeitos, e que correspondem à forma como se articulam as relações entre o plano individual e a estrutura social. São eles: 
1. Localização no tempo e no espaço (location in time and place): essa dimensão remete à forma como a experiência individual é interdependente de um momento histórico, de uma sociedade e de uma cultura. No caso específico do empreendedor social, percebe-se, por meio das atribuições de sentido às práticas e sua contextualização no cenário do próprio país, a forma como esse ator corresponde a uma ancoragem referencial específica, por mais que, em tese, a utopia de "mudar o mundo", presente nas alusões à sua atividade, remeta à ideia de predisposições e valores que possam ser entendidos como "universais". O que se pretende mudar e a forma como se edita o mundo em torno de sua atuação fazem do empreendedor social um catalisador das vozes que atravessam o seu tempo e o seu lugar de fala, delimitado pelo pertencimento a uma comunidade imaginada (Anderson, 2005).

2. Vidas interligadas (linked lives): as relações sociais representadas nas narrativas de vida configuram o sentido de participação comunitária, da ideia de trabalho cooperativo, de agentes que afetam e são afetados, na perspectiva de uma troca de base comunicacional, interacional (Sodré, 2006). No plano discursivo, as teias de sentido se estabelecem na forma como o "eu" se multiplica em conexões com o outro, seja na delimitação da diferença, seja principalmente na construção do nós que faz da fala do sujeito isolado um nó de uma rede de afetos e objetivos compartilhados, de empreendimentos que se fazem na pluralidade de vidas mobilizadas.

3. Orientação pessoal das ações (human agency): busca-se compreender as motivações de caráter pessoal, o percurso de vida construído que leva o sujeito a ter determinados objetivos e necessidades específicas, a partir dos quais toma decisões e segue sua trajetória. $\mathrm{O}$ empreendedor social, ao elaborar o discurso a respeito de sua atuação, dá pistas sobre sua orientação, sobre aquilo em que acredita e pelo 
que faz valer a sua luta, a sua persistência, as suas recompensas, as suas vitórias, mas também possibilita compreender a dimensão de seus fracassos, de seus sonhos frustrados, das metas não alcançadas.

4. Momentos da vida (timing of lives): leitura da forma como a vida narrada se estabelece a partir de marcos, de momentos de transformação, de movimentos de adaptação pessoal às influências externas, à passagem do tempo, à mudança de ciclos da experiência. Os períodos que constituem a trajetória permitem analisar a maneira como os significados do presente são colocados em conexão com a memória. A trajetória de vida, organizada a partir do eixo da existência como empreendedor social, estabelece uma reelaboração de marcos temporais e acontecimentos pessoais que vão dar a ideia do percurso, das veredas narrativas que desembocam em uma experiência marcada no presente e projetada para o futuro.

O percurso da vida, a partir dos quatro elementos a serem observados, de acordo com a proposta de Giele e Elder Jr. (1998), traduz-se, dessa forma, em narrativas que mobilizam elementos contextuais do cenário macrossocial, expressões da subjetividade materializadas na forma de motivações e metas pessoais, representações de interações sociais e de modos de existir em comunidade, articulações de feixes de memória que se conectam a atuação humana no momento presente.

Um ponto a destacar na pesquisa de campo relaciona-se com as práticas do consumo e à forma como elas se ajustam ou não ao habitus (Bourdieu, 2003) de um ator que, na direção apontada inicialmente por Weber e atualizada por Boltanski e Chiapello (2009), segue uma ética em relação às coisas do mundo e, em função dela, traça fragmentos de seu estilo de vida em uma narrativa alinhavada pelo tema do empreendedorismo social. Amaya (2004) analisa a forma como o consumo serve de balizador da experiência 
nas narrativas de jovens colombianos acerca da vida e da morte, pois é a partir do gosto por determinados filmes, livros e canções que a narrativa faz emergir uma forma de subjetividade calcada no possível compartilhamento de sentidos com o outro, em uma forma de extimidade (Sibilia, 2008).

Interessa-nos perceber a maneira como, a partir da observação de entrevistas já realizadas para este estudo, há um paradoxo fundamental em relação à negação do consumo ou o discurso anticonsumo, que é intrínseco a um ator social que exerce a função de "mudar o mundo", mesmo que seja o mundo à sua volta. Nesse mundo a ser transformado, em grande parte das narrativas de vida, o consumo surge como vilão, com o sentido do consumismo, ou do consumo como supérfluo, na linha já apontada pela crítica à classe ociosa feita por Veblen (1987). A questão feita a respeito do gosto ou do consumo que identifica esse sujeito faz surgir automaticamente essa crítica e negação da própria vinculação social a partir de práticas de consumo, seja ele de qualquer natureza. No entanto, ao se observar grande parte das iniciativas propostas pelos empreendedores sociais entrevistados, o consumo, apropriado e adequado ao mundo editado pelo projeto social, aparece como parte fundamental das operações do empreendimento, principalmente no que se refere à chamada sustentabilidade, ou seja, a viabilização financeira da ideia, dentro de uma economia de mercado, por mais que seja uma proposta de ressignificação das mercadorias e da leitura neoliberal tradicional do que é a economia capitalista.

Dessa forma, a proposta de produzir em sistema cooperativo, a fim de resgatar mulheres idosas do isolamento social, como é o caso do Vintage For a Cause $e^{7}$, projeto desenvolvido na cidade do Porto, oferece ao mercado um vestuário que teria um valor social agregado, que deveria ser considerado pelo consumidor visado pela iniciativa. O consumo, nesse contexto, é significado como processo redentor e a mercadoria é um signo que representa certo desvio do status quo, porém, reitera a dinâmica capitalista 
de produção, circulação e consumo de bens - que, em última instância, visam atender aos gostos e desejos individuais, sendo colocados em forma de opção de escolha, em meio a gama de ofertas do mercado.

\section{Sobre o roteiro da entrevista}

Neste tópico, apontamos o que há de mais relevante na estratégia de abordagem dos empreendedores sociais, na interação com o pesquisador, da qual resulta uma narrativa que é marcada no tempo, no espaço e em determinada situação comunicacional. $\mathrm{O}$ tema do empreendedorismo social é o eixo narrativo a partir do qual a vida é editada e articulada e em torno do qual o sujeito se posiciona reflexivamente sobre algo que remete à ideia de campo, na perspectiva de Bourdieu (2003). Mesmo que não o seja em todos os elementos que caracterizam um campo, há uma comunidade imaginada que estabelece redes de contato, pontos de encontro, há regras internas, há tensionamentos de outros campos, enfim, há um caráter estruturado e estruturante, que leva ao reconhecimento do empreendedor social como tal. Encontramos os prêmios atribuídos aos seus atores exemplares, há formas de legitimação e delimitação do outro em zonas fronteiriças tênues, há um espírito comum que articula subjetividades para causas, desafios, sentimentos e metas compartilhados.

Uma das questões centrais do roteiro se refere à grande transformação ocorrida na vida do sujeito entrevistado. Uma questão simples, porém, de grande simbologia para esse ator social, em sua constituição imaginária: o empreendedor social seria, em essência, um transformador da sociedade, a partir de suas ideias e sua ação. Um dos maiores porta-vozes do campo, a Ashoka, rede internacional que dá visibilidade aos empreendedores sociais e se coloca como plataforma de legitimação das boas práticas, utiliza uma denominação que sintetiza esse campo semântico: os empreendedores sociais são chamados de changemakers. 
Nesse contexto, trabalhamos com a hipótese, confirmada nas observações iniciais do trabalho de campo, de que a transformação empreendida por esse ator é antecedida por uma transformação na própria vida, ou seja, um empreender a si mesmo para se abrir a causas que são associadas a comunidades, a redes de pessoas, a mundos diversos. Os motivos são dos mais variados: de traumas na vida pessoal a despertares de consciência a partir do conhecimento, tanto acadêmico quanto da experiência cotidiana, que levam a uma articulação da vida em dois momentos distintos, divididos por esse eixo de transformação pessoal. Algo que se assemelha à tese de Illouz (2007), quando trata da narrativa terapêutica, fruto da intersecção entre a autoajuda e a psicologia positiva, apreendida nas narrativas do eu (Sibilia, 2008) que organizam o passado como algo a ser transformado, como um desvio do caminho que deveria ser tomado e que é identificado com a realidade presente.

Duas questões se referem à memória, uma espécie de volta à infância: o exercício de lembrar e reconstituir narrativamente um momento da fase inicial da vida e algum sonho de infância que esteja relacionado a uma atividade profissional - em certas narrativas de empreendedores sociais tornou-se ocasião para estabelecer intersecções entre uma forma autêntica de ser, associada à figura da criança, com a vida adulta do gestor de um empreendimento social, às voltas com os problemas, com a burocracia, com o incentivo limitado da sociedade civil, de maneira geral. $\mathrm{O}$ adulto observa a criança que já foi e, em algumas situações, percebe a semente que lá estava a ser germinada e que culminou nas escolhas feitas recentemente.

\section{Considerações finais}

Assim como a narrativa de transformação, a memória é essencialmente um tempo narrativo - um ponto numa trajetória que conjuga passado, presente e futuro -, articulado no momento presente, na situação da entrevista, com a projeção de 
um auditório social (Bakhtin, 1997), calculado a partir da presença do pesquisador que faz questionamentos e que será o mediador dessa experiência narrada, transmitindo-a e analisando-a, para estabelecer diálogos em outro campo, no caso, o acadêmico.

Esse cálculo, obviamente, é uma situação balizadora do que é narrado, é o elemento agenciador da edição da própria história e da leitura do mundo à sua volta. Ao fim e ao cabo, conceber uma narrativa de si é publicizar-se, é tornar-se visível, é mobilizar a língua para dar conta de representar a experiência. Processo imerso em subjetividade, em afetações mútuas, em situações enunciativas que não são repetíveis - acontecem no hic et nunc da realização da entrevista. Afirma-se, assim, a vinculação da pesquisa ao campo da comunicação, posto que os processos que envolvem a narração da vida e a atribuição de sentido à atividade do empreendedorismo social são essencialmente discursivos, estabelecendo a intersecção entre comunicação, trabalho e subjetividade.

Dessa forma, buscamos apreender os mundos possíveis sonhados pelos empreendedores e o espírito do tempo manifestado na forma como os entrevistados editam a própria história, como fazem o diagnóstico do contexto em que se inserem e como se projetam, no presente e no futuro, como transformadores.

\section{REFERÊNCIAS}

AMAYA, José Fernando. Menos querer más de la vida: concepciones de vida y muerte en jóvenes urbanos. Bogotá: Universidad Centreal y Siglo del Hombre Editores, 2004.

ANDERSON, Benedict. Comunidades imaginadas: reflexões sobre a origem e a expansão do nacionalismo. Lisboa: Edições 70, 2005.

ARFUCH, Leonor. O espaço biográfico: dilemas da subjetividade contemporânea. Rio de Janeiro: EdUerj, 2010. BAKHTIN, Mikhail. Marxismo e filosofia da linguagem. São Paulo: Hucitec, 1997.

BOLTANSKI, Luc; CHIAPELLO, Ève. O novo espírito do capitalismo. São Paulo: WMF Martins Fontes, 2009. BOURDIEU, Pierre. O poder simbólico. Rio de Janeiro: Bertrand Brasil, 2003. 
EHRENBERG, Alain. O culto da performance: da aventura empreendedora à depressão nervosa. Aparecida: Ideias \& Letras, 2010.

GIELE, Janet; ELDER JR., Glen. Life course research: development of a field. In GIELE, Janet; ELDER JR. (Eds.). Methods of life course research: qualitative and quantitative approaches. Califórnia; Londres: Sage, 1998. pp. 5-27.

ILLOUZ, Eva. Intimidades congeladas: las emociones en el capitalismo. Buenos Aires; Madrid: Katz Eds, 2007. LOPES, Mónica. Empreendedorismo. In Dicionário das crises e alternativas. Coimbra: Almedina; CES, 2012. pp. 86-87.

MARX, Karl. Trabalho estranhado e propriedade privada. In: ANTUNES, Ricardo (Org.). A dialética do trabalho: escritos de Marx e Engels. São Paulo: Expressão Popular, 2004. pp. 173-195.

MATTELART, Armand. História da utopia planetária: da cidade profética à sociedade global. Porto Alegre: Sulina, 2002.

SIBILIA, Paula. O show do eu: a intimidade como espetáculo. Rio de Janeiro: Nova Fronteira, 2008.

SODRÉ, Muniz. As estratégias sensíveis: afeto, mídia e política. Petrópolis: Vozes, 2006.

SOUZA, Jessé. Os batalhadores brasileiros: nova classe média ou nova classe trabalhadora? Belo Horizonte: Ed. UFMG, 2010.

VEBLEN, Thorstein. A teoria da classe ociosa: um estudo econômico das instituições. São Paulo: Abril Cultural, 1987.

\section{NOTAS}

1 A primeira versão deste artigo, com resultados parciais de pesquisa de pós-doutorado no exterior (financiamento pela CAPES, processo nº 10542-12-4), foi apresentada no XIII Congresso Internacional IBERCOM - Comunicación, Cultura e Esferas de Poder, realizado na Universidade de Santiago de Compostela, Santiago de Compostela, de 29 a 31 de maio de 2013, tendo sido revisada para esta publicação.

2 Disponível em: <http://www.ies.org.pt/conhecimento/o_que_e_empreendedorismo_social/>. Acesso em: 24 abr. 2013.

3 Disponível em: <http://www.ies.org.pt/conhecimento/o_que_e_empreendedorismo_social/>. Acesso em: 24 abr. 2013.

4 Disponível em: $<$ http://www.ies.org.pt/perguntas_frequentes/qual_a_diferenca_entre_empreendedorismo_ e_empreendedorismo_social/>. Acesso em: 24 abr. 2013.

5 Disponível em: <https://www.facebook.com/bancodeinovacaosocial.pt?ref=ts\&fref=ts>. Acesso em: 25 abr. 2013. 
6 Disponível em: <http://www.mapadaparticipacao.org.br/>. Acesso em: 24 abr. 2013.

7 Disponível em: <http://www.vintageforacause.pt>. Acesso em: 24 abr. 2013.

\section{Endereço do autor:}

Vander Casaqui <vcasaqui@yahoo.com.br>

Escola Superior de Propaganda e Marketing (ESPM)

Programa de Pós-Graduação em Comunicação e Práticas de Consumo

Rua Dr. Álvaro Alvim, 123 - Vila Mariana

CEP 04018-010, São Paulo, SP, Brasil 